\title{
Thrombosis associated with mycoplasma pneumoniae infection (Review)
}

\author{
JINGWEI LIU and YUMEI LI
}

\begin{abstract}
Department of Pediatrics Intensive Care Unit, The First Hospital of Jilin University, Changchun, Jilin 130021, P.R. China
\end{abstract}
Received February 16, 2021; Accepted June 18, 2021

DOI: $10.3892 /$ etm.2021.10399

\begin{abstract}
Mycoplasma pneumoniae is a common pathogen causing respiratory infections in children and adults. In addition to respiratory diseases, Mycoplasma pneumoniae is also involved in numerous extrapulmonary diseases. Thrombosis is an extrapulmonary manifestation associated with Mycoplasma pneumoniae infection. In recent years, an increasing number of case reports have been published identifying thrombosis secondary to Mycoplasma pneumoniae infection. In the present study, the available relevant literature in English available on PubMed, Medline and Web of Science was consulted. The results of the present study demonstrated that in patients with thrombosis caused by Mycoplasma pneumoniae infection, some of the factors causing thrombosis are transient and some are due to hereditary thrombophilia. Following timely treatment, the majority of patients recovered completely but some patients had a poor prognosis. The present review focuses on the pathogenesis, clinical features, treatment and prognosis of this crucial issue, which contributes toward the understanding of the disease.
\end{abstract}

\section{Contents}

1. Introduction

2. Methods

3. Location of thrombosis

4. Thrombosis onset time from Mycoplasma pneumoniae infection

5. Laboratory examination for thrombosis

6. Pathogenesis of thrombosis

7. Treatment of thrombosis

8. Prognosis of thrombosis

9. Prevention of thrombosis

Correspondence to: Dr Yumei Li, Department of Pediatrics Intensive Care Unit, The First Hospital of Jilin University, 1 Xin Min Street, Changchun, Jilin 130021, P.R. China

E-mail: ym_li@jlu.edu.cn

Key words: mycoplasma pneumoniae, thrombosis, infection, pathogenesis, prognosis
10. Limitations

11. Conclusions

\section{Introduction}

Mycoplasma pneumoniae is the smallest self-replicating organism in terms of genome length and cellular size (1). Mycoplasma pneumonia occurs worldwide throughout the year, but it is more common in the summer or early autumn (2) and may be spread from person to person through aerosols (3). These infections can be detected by culture, serology and molecular-based assays. Serum antibody detection is the most frequently used method for retrospective diagnosis of Mycoplasma pneumoniae infection (4). Possible mechanisms of damage to host cell by mycoplasma pneumonia is through competition for precursors, adherence to cells, fusion to the cell and cytopathic effects (5).

Respiratory infection is a common disease, which can be caused by Staphylococcus aureus $(6,7)$, Mycoplasma pneumoniae and other pathogens. Tracheobronchitis is another very common clinical manifestation induced by Mycoplasma pneumoniae infection; however, pneumonia is the most important clinical illness associated with Mycoplasma pneumoniae infections (2). It is well known that Mycoplasma pneumoniae is a common cause of community-acquired pneumonia in children and adults (8). In endemic periods, 4-8\% of all cases of community-acquired pneumonia were attributed to Mycoplasma pneumoniae and during incidence peaks, up to $40 \%$ of community-acquired pneumonia cases were from Mycoplasma pneumonia (9). Mycoplasma pneumoniae infection is generally self-limiting and mild; however, in some patients it may develop into a severe or life-threatening disease (10). There are also many asymptomatic children who carry Mycoplasma pneumoniae in their upper respiratory tract and it may persist in the respiratory tract for weeks or even months after infection (11).

Aside from respiratory diseases, Mycoplasma pneumoniae is also involved in the development of some extra-respiratory diseases (12). Previous studies have reported that Mycoplasma pneumoniae is involved in extra-respiratory diseases of the skin, musculoskeletal $(13,14)$, cardiovascular $(15,16)$, hematological $(17,18)$, gastro-intestinal $(19,20)$, neurological $(21,22)$ and renal $(23)$ systems. These conditions may have variable clinical features 
and may appear in immunologically predisposed children with recurrent or persistent Mycoplasma pneumoniae infection (24). Mycoplasma pneumoniae can involve almost any part of the body and can develop into extensive extrapulmonary manifestations (12). A retrospective study of children with Mycoplasma pneumoniae infection demonstrated that delayed effective treatment was associated with extrapulmonary manifestations (25). A prospective study revealed that the serum immunoglobulin E level in children with Mycoplasma pneumoniae-related extrapulmonary diseases was significantly higher compared with in children with only Mycoplasma pneumoniae-related respiratory illnesses (26). Certain individuals, who are prone to produce immunoglobulin E, may be predisposed to develop extra-respiratory diseases associated with Mycoplasma pneumoniae acute infections (27).

Thrombosis is one of the extra-respiratory manifestations associated with Mycoplasma pneumoniae infection (12). With an improved understanding of Mycoplasma pneumoniae, case reports of thrombosis associated with Mycoplasma pneumoniae infection are increasing (28-61). Thrombosis is a major cause of mortality and disability worldwide (62). Arterial thrombosis is usually associated with plaque rupture, which triggers platelets to develop platelet rich clots; however, venous thromboembolism is associated with endothelial dysfunction and blood stasis, leading to fibrin- and erythrocyte-rich thrombus (62). Following Mycoplasma pneumoniae infection, thrombosis may occur in a different part of the body, sometimes affecting the prognosis of the disease $(29,30)$. The present review summarizes the pathogenesis, clinical features, treatment and prognosis of thrombosis induced by Mycoplasma pneumoniae infection in order to better understand this complication.

\section{Methods}

Comprehensive searches of PubMed, Medline, and Web of Science were performed to identify all published reports on patients with thrombosis associated with Mycoplasma pneumoniae infection. Search terms included: 'Mycoplasma pneumoniae' and 'thrombus' or 'embolism' or 'thrombosis' or 'thrombotic' or 'thromboembolism'. Results published between January 1970 and December 2020 were included. Only full-text, English-language papers were included. Duplicate publications and irrelevant topics were excluded. Data collected included the location of thrombosis, thrombosis onset time since Mycoplasma pneumoniae infection, laboratory examination regarding thrombosis, and pathogenesis of thrombosis.

\section{Location of thrombosis}

Patients with Mycoplasma pneumoniae infection may present with thrombus in almost any part of the body (Tables I-VI) Thrombosis caused by Mycoplasma pneumoniae infection was most reported in the head and neck, followed by in the limbs. Certain patients with normal chest radiography and Mycoplasma pneumoniae infection also developed thrombi $(28,33,34)$. Certain patients developed thrombi in only one part of the body, while others developed thrombi in multiple parts. One patient developed an aortic thrombus, a right peroneal artery embolus, a splenic infarct and a renal infarct (28).

\section{Thrombosis onset time from Mycoplasma pneumoniae infection}

Cerebral infarction developed 2 days to 3 weeks after Mycoplasma pneumoniae infection (29-31,33-41,43,44). Chest imaging of certain patients revealed pulmonary embolism 11-29 days after Mycoplasma pneumonia infection (52). A previous case report identified a cardiac thrombus 4 days after Mycoplasma pneumoniae infection (46). Thrombi in abdominal organs developed $\sim 1$ week to 1 month after Mycoplasma pneumoniae infection (28,48-51). Thrombosis in the extremities appeared $\sim 1-2$ weeks after Mycoplasma pneumoniae infection (28,41,53-57) while thrombotic microangiopathy occurred 3 days to 3 weeks after infection $(58,59,61)$.

\section{Laboratory examination for thrombosis}

Children with Mycoplasma pneumoniae pneumonia had higher plasma fibrinogen and D dimer levels than healthy children (63). They also had shorter prothrombin and activated partial thromboplastin times (63). The increased fibrinogen and D-dimer levels may induce a hypercoagulable state, which appears 6-15 days after Mycoplasma pneumoniae pneumonia onset (32). Extensive coagulation studies were performed, including plasma levels of clotting factors, proteins $\mathrm{C}$ and $\mathrm{S}$, plasminogen, antithrombin III, lupus anticoagulant, sickle cell anemia, homocysteine antiphospholipid syndrome, disorders of fibrinolysis, anticardiolipin antibody and cold agglutinins $(30,39,43,48)$. Tests for inherited thrombophilia are controversial and certain studies have suggested that these tests for inherited thrombophilia should never be performed (64). Inherited thrombophilia is usually identified by a coagulation specialist based on their personal and family history of venous thromboembolism, but a diagnosis can be made without the results of these tests (64).

\section{Pathogenesis of thrombosis}

Mycoplasma pneumonia may directly cause local thrombosis occlusion by affecting the vascular wall without systemic hypercoagulability (65). An autopsy of a patient with acute myocardial infarction revealed that Mycoplasma pneumoniae was present in the unstable segments of the intima (66). Furthermore, Mycoplasma pneumoniae is frequently found in atherosclerotic plaques (67). In addition, systemic hypercoagulability through the activation of chemical mediators, including complement, may result in thrombotic vessel occlusion (65).

Familial thrombophilia. Some of the included patients were diagnosed with familial thrombophilia and Mycoplasma pneumoniae infection. A man with Mycoplasma pneumoniae infection developed thrombi due to a homozygous methylenetetrahydrofolate mutation, increased homocysteine concentration and decreased folic acid level (33). Another boy with a heterozygous methylenetetrahydrofolate 
Table I. Summary of thrombosis cases in the brain and neck associated with Mycoplasma pneumoniae infection.

\begin{tabular}{cclc}
\hline No. & Pulmonary infection & \multicolumn{1}{c}{ Thrombus or infarction site } & $($ Refs.) \\
\hline 1 & Yes & Right middle cerebral artery & $(29)$ \\
2 & Yes & Right vertebral and basilar arteries & $(30)$ \\
3 & Yes & Right lenticulostriate artery & $(31)$ \\
4 & Yes & Right middle cerebral artery & $(35)$ \\
5 & Yes & Left middle cerebral artery & $(36)$ \\
6 & Yes & Deep cerebral and dural venous sinus & $(37)$ \\
7 & Yes & Left carotid artery & $(38)$ \\
8 & No & Left centrum semiovale & $(34)$ \\
9 & No & Right vertebral and midbasilar arteries & $(33)$ \\
10 & Yes & Left posterior cerebral artery & $(39)$ \\
11 & Yes & Left internal carotid artery and the middle cerebral artery & $(40)$ \\
12 & Yes & Left middle cerebral artery & $(41)$ \\
13 & Yes & Right anterior cerebral artery/middle cerebral artery and left middle cerebral artery & $(42)$ \\
14 & Yes & Acute infarctions of both posterior cerebral arteries and left middle cerebral artery & $(43)$ \\
& & territories & $(44)$ \\
15 & Yes & Left middle cerebral artery & $(45)$ \\
16 & Unknown & Cerebrovascular infarction & \\
\hline
\end{tabular}

Table II. Summary of thrombosis cases in the heart and aorta associated with Mycoplasma pneumoniae infection.

\begin{tabular}{|c|c|c|c|}
\hline No. & Respiratory infection & Thrombus site & (Refs.) \\
\hline 1 & Yes & Right ventricle & (46) \\
\hline 2 & Yes & Left ventricle & $(47)$ \\
\hline 3 & Yes & Tricuspid valve chordae tendineae, under the tricuspid valve, and left atrium & $(32)$ \\
\hline 4 & No & Aorta & (28) \\
\hline
\end{tabular}

Table III. Summary of thrombosis cases in the abdomen associated with Mycoplasma pneumoniae infection.

\begin{tabular}{llll}
\hline No. & Respiratory infection & Thrombus site & (Refs.) \\
\hline 1 & Yes & Splenic & $(48)$ \\
2 & No & Splenic & $(49)$ \\
3 & No & Splenic & $(50)$ \\
4 & Yes & Splenic & $(51)$ \\
5 & Yes & Splenic & $(51)$ \\
6 & No & Renal and splenic & $(28)$ \\
7 & Yes & Splenic artery, celiac trunk artery, and superior mesenteric artery & $(32)$ \\
\hline
\end{tabular}

mutation also developed cerebral infarction following Mycoplasma pneumoniae infection, but his homocysteine concentration remained normal(30). Methylenetetrahydrofolate enzyme dysfunction may cause hyperhomocysteinemia (68). Patients with increased homocysteine levels are prone to develop thrombi (69). Hyperhomocysteinemia may lead to endothelial dysfunction, by suppressing nitric oxide production and endothelial nitric oxide synthase activity (70). However, another study demonstrated that hyperhomocysteinemia did not increase the risk of developing venous thrombus following adjusting for confounding factors (71). One case described a girl with thrombosis secondary to Mycoplasma pneumoniae pneumonia who was diagnosed with familial antithrombin III deficiency (56). Antithrombin is a natural anticoagulant which suppresses active clotting factors particularly thrombin and activated factor X (72,73). Patients with antithrombin deficiency have a significantly increased risk of thromboembolism, particularly in the venous circulation (74). 
Table IV. Summary of thrombosis cases in the lung associated with Mycoplasma pneumoniae infection.

\begin{tabular}{llll}
\hline No. & \multicolumn{1}{c}{ Thrombus site } & (Refs.) \\
\hline 1 & Yes & Lung & $(52)$ \\
2 & Yes & Left lung & $(53)$ \\
3 & Yes & Right lung & $(54)$ \\
4 & Yes & Lung (including pulmonary artery and vein) & $(32)$ \\
\hline
\end{tabular}

Table V. Summary of thrombosis cases in the limbs associated with Mycoplasma pneumoniae infection.

\begin{tabular}{|c|c|c|c|}
\hline No. & Pulmonary infection & Thrombus site & (Refs.) \\
\hline 1 & Yes & Right popliteal artery and its distal branches & (55) \\
\hline 2 & Yes & Fibular vein, posterior tibial vein, and femoral vein & (53) \\
\hline 3 & Yes & Left popliteal vein & (54) \\
\hline 4 & Yes & Left femoral vein & $(56)$ \\
\hline 5 & Unknown & $\begin{array}{l}\text { Left-sided popliteal vein, femoral vein, external and internal iliac veins, and } \\
\text { common iliac vein }\end{array}$ & (57) \\
\hline 6 & No & Right peroneal artery & (28) \\
\hline 7 & Yes & Both femoral veins & (41) \\
\hline 8 & Yes & $\begin{array}{l}\text { Popliteal artery, posterior tibial artery, external iliac vein, common iliac vein, } \\
\text { common femoral vein, great saphenous vein, internal iliac vein cephalic vein, and } \\
\text { superficial vein of cubital fossa }\end{array}$ & (32) \\
\hline
\end{tabular}

Table VI. Summary of thrombotic microangiopathy cases associated with Mycoplasma pneumoniae infection.

\begin{tabular}{lllr}
\hline No. & Respiratory infection & \multicolumn{1}{c}{ Thrombotic microangiopathy } & $($ Refs.) \\
\hline 1 & Yes & Thrombotic thrombocytopenic purpura & $(58)$ \\
2 & Yes & Hemolytic uremic syndrome & $(59)$ \\
3 & Unknown & Thrombotic thrombocytopenic purpura & $(60)$ \\
4 & Yes & Thrombotic thrombocytopenic purpura & $(61)$ \\
\hline
\end{tabular}

Antiphospholipidantibodies. Certain studies and case reports have demonstrated that patients with thrombosis secondary to Mycoplasma pneumoniae infection were positive for anticardiolipin antibodies, $\beta 2$-glycoprotein antibodies or lupus anticoagulant antibodies $(28,32,46,51,53,54)$. These aforementioned antibodies were transient and became negative in certain patients 3-6 months after initial disease onset $(28,32,46,53,54)$. Anticardiolipin antibody, $\beta 2$-glycoprotein antibody and lupus anticoagulant antibody are all antiphospholipid antibodies, which reacts to phospholipids, phospholipid-protein complexes and phospholipid-binding proteins $(75,76)$. The antiphospholipid antibodies contribute toward the formation of a thrombus (76). Antiphospholipid antibodies cause thrombosis through protein phosphatase $2 \mathrm{~A}$ activation via apolipoprotein E receptor 2, disabled-2 and src homology domain-containing transforming protein 1 complex formation in the endothelium (77). Patients with thrombosis and positive antiphospholipid antibodies are also likely to develop thrombosis again (78).
Anti-prothrombin antibodies. Certain patients with thrombosis associated with Mycoplasma pneumoniae infection were positive for anti-prothrombin antibodies, which was resolved 3 months after the acute illness $(48,54)$. Anti-prothrombin antibody is not a criterion for diagnosing anti-phospholipid syndrome and is referred to as noncriteria antibody (79). Anti-prothrombin antibody increases the risk of thrombosis $(80,81)$.

Increased coagulation factors. Certain patients with thrombosis secondary to Mycoplasma pneumoniae infection had increased factor VIII (28). However, this phenomenon was transient, and the factor VIII levels were normal 3 months after the acute disease (28). Certain patients with thrombosis induced by Mycoplasma pneumoniae infection had increased von Willebrand factor activity and increased levels of intrinsic pathway clotting factors, including factor VIII, factor IX and factor XI (48). These increased coagulation factors contribute toward the formation of thrombosis. 


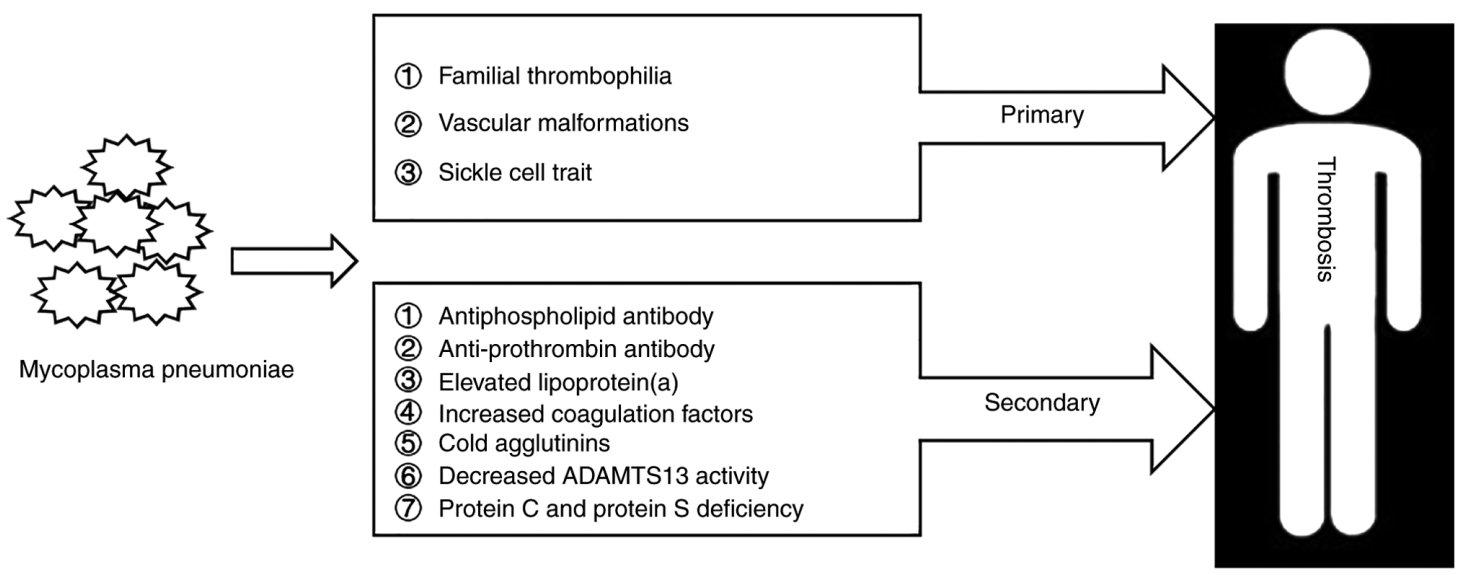

Figure 1. Patients with Mycoplasma pneumoniae infection may develop thrombi in any part of the body, which is due to primary and secondary factors.

Cold agglutinins. Cold agglutinins were present in certain patients with thrombosis induced by Mycoplasma pneumoniae infection $(46,48)$. Cold agglutinins induce hemolysis and anemia by binding to the erythrocyte antigen at a lower temperature and triggering the classical complement pathway (82). Hemolysis may contribute toward thrombosis by increasing circulating procoagulant microparticles (83), hyperactivating hemoglobin-bound von Willebrand factor multimers (84) and promoting platelet aggregation (85).

Lipoprotein (a). Certain patients with thrombosis induced by Mycoplasma pneumoniae infection had increased lipoprotein (a) (51). Lipoprotein contributes toward thrombotic disorder (86). Patients with higher levels of lipoprotein (a) had impaired fibrinolysis (86), which may be induced by interfering with the binding of plasminogen to fibrin (87), inhibiting plasminogen activation (88), and decreasing the generation of plasmin (89).

Vascular malformations. A boy without an inferior vena cava developed deep venous thrombosis and Mycoplasma pneumoniae infection (57). Certain vascular malformations, including the absence of the inferior vena cava contribute toward the development of thrombosis (90). There have also been other reports of thrombosis associated with vascular malformations (91-93). Vascular malformations are complex congenital diseases, which occur due to abnormalities during the process of vasculogenesis (94). Certain vascular malformations are characterized by slow-flow (94). Slow deep venous flow in the lower extremities correlates with an increased rate of subsequent deep venous thrombosis (95). Slow-flow of vascular malformations serves a role in the process of thrombosis associated with Mycoplasma pneumoniae infection. A previous study supported the role of Mycoplasma pneumoniae in the formation of aneurysms (96). A patient with Mycoplasma pneumoniae infection presented with aortic and subclavian aneurysm and acute cerebral infarction (34). There is a significant risk of thrombosis in patients with an aneurysm (97).

Sickle cell trait. One case report described a boy with Mycoplasma pneumoniae infection who developed a posterior cerebral artery occlusion; he also had the sickle cell trait and a normal thrombophilia examination (39). Previous case reports have described patients with the sickle cell trait who formed a thrombus (98-100). Sickle cell trait is a heterozygous form of sickle cell anemia (101). Patient with sickle cell trait have slightly decreased erythrocyte deformability, increased erythrocyte aggregation (102) and increased blood viscosity $(101,103,104)$. These characteristics may serve an important role in the development of thrombosis associated with Mycoplasma pneumoniae infection.

ADAMTS13 enzyme. Mycoplasma pneumoniae infection may affect the activity of the ADAMTS13 enzyme. A woman with thrombotic microangiopathy associated with Mycoplasma pneumonia infection had high anti-ADAMTS13 antibodies at the beginning of infection and her plasma ADAMTS13 enzyme activity was normal 1 month after clinical resolution (58). Another patient with hemolytic uremic syndrome complicated by Mycoplasma pneumoniae infection presented with a moderate decrease in ADAMTS13 activity following admission, but it increased to the normal levels during follow-up (59). The protease ADAMTS-13 may cleave the von Willebrand factor and decrease its thrombogenicity (105). Acquired deficiency of ADAMTS-13 is secondary to sepsis (106). Deficiency of ADAMTS-13 may cause thrombotic microangiopathy (107). Inflammation may affect ADAMTS13 activity by oxidative modification (108). During inflammation, interleukin-6 partially suppresses ADAMTS13 activity (109), while interleukin-8 and tumor necrosis factor increase the release of the von Willebrand factor, which exceeds the processing capacity of ADAMTS13 and leads to thrombosis (109).

Protein $C$ and protein $S$. Acute hepatitis is an extrapulmonary disease induced by Mycoplasma pneumonia (1). Abnormal liver function is not infrequently seen in patients with Mycoplasma pneumoniae infection (1) as proteins $\mathrm{C}$ and $\mathrm{S}$ are predominantly produced by hepatocytes. Activated protein $\mathrm{C}$ inhibits thrombosis by deactivating activated factors V and VIII. Protein S serves as a co-factor during this process (110-112). Patients with hepatic cirrhosis usually have low levels of protein $\mathrm{C}$ and high levels of factor VIII. This 
increased factor VIII/protein C ratio contributes toward the development of a thrombophilia state (113). The insufficiency of protein $\mathrm{C}$ destroys the balance between procoagulant and anticoagulant proteins; therefore, individuals are prone to develop thromboembolism (111). Abnormal liver function may affect the synthesis of protein $\mathrm{C}$ and protein $\mathrm{S}$ in patients with Mycoplasma pneumoniae infection, thereby predisposing them to thrombosis. There were several reported cases of thrombosis and Mycoplasma pneumoniae infection, which reported low levels of protein $\mathrm{S}(30-32,54)$. One month after the initial disease, the level of protein $\mathrm{S}$ had increased to the normal range (31), while another study reported that the protein $\mathrm{S}$ activity became normal after 6 months (32).

\section{Treatment of thrombosis}

In addition to treatment with antibiotics, patients underwent various methods to treat thrombosis associated with Mycoplasma pneumoniae infection. In cases where the thrombus partially detached and was almost floating in the right ventricle, it was removed by cardiac surgery (46). Due to shape change and size reduction of the thrombus, another patient with left ventricular thrombus and Mycoplasma pneumoniae infection also underwent urgent surgery (47). In another case, an extremity deep vein thrombosis in a man with mycoplasma pneumonia was not absorbed despite strong anticoagulant therapy, and therefore a filter was implanted into his inferior vena cava to prevent the thromboembolism recurring (41). Another boy with posterior cerebral artery occlusion secondary to Mycoplasma pneumoniae infection was treated with a low dose of aspirin (39). In other cases, thrombolytic therapy with urokinase was performed in severe clinical condition $(37,55)$.

\section{Prognosis of thrombosis}

Following anticoagulant treatment, the thrombus absorption time of the majority of patients was more than 3 months, but was 1.5 to 3 months in some others. However, in the majority of patients, thrombus-related symptoms disappeared within 1 month (32). However, certain patients may also have sequelae, particularly patients with cerebral thrombi. In one case, a boy with Mycoplasma pneumoniae pneumonia and cerebral infarction still had poor right hand grip power at the 6-month follow-up visit (40). In another case, an adult with Mycoplasma pneumoniae pneumonia and cerebral infarction slowly recovered from hemiplegia but continued to have a residual deficit (29). Certain case reports with cerebral infarction secondary to Mycoplasma pneumoniae pneumonia reported that patients' neurological symptoms completely resolved $(31,34,41)$.

\section{Prevention of thrombosis}

The risk factors of thrombosis in patients with Mycoplasma pneumoniae infection should be identified. Pulmonary consolidation and high levels of inflammatory markers were found to be risk factors for patients with severe Mycoplasma pneumoniae pneumonia to develop thrombus (32).
Predisposing factors associated with a hypercoagulable state also contribute toward thrombosis. One study suggested that clinicians should weigh the risks and benefits of low molecular weight heparin prophylaxis in patients with mycoplasma infection at risk for thrombosis (114).

\section{Limitations}

In-depth studies into the mechanism of how Mycoplasma pneumoniae infection causes thrombosis have not been published; therefore, the summary of the mechanism in this review may be too superficial.

\section{Conclusions}

Further attention should be paid to the extrapulmonary manifestations associated with Mycoplasma pneumoniae infection, particularly thrombosis. The mechanism of thrombosis in patients with Mycoplasma pneumoniae infection includes numerous factors, and thrombi induced by Mycoplasma pneumoniae infection may occur in any part of the body (Fig. 1). Early diagnosis and timely therapy may improve the prognosis of these patients.

\section{Acknowledgements}

Not applicable.

\section{Funding}

No funding was received.

\section{Availability of data and materials}

Not applicable.

\section{Authors' contributions}

YL designed the study. JL wrote the manuscript. Data authentication is not applicable for this study. Both authors read and approved the final manuscript.

\section{Ethics approval and consent to participate}

Not applicable.

\section{Patient consent for publication}

Not applicable.

\section{Competing interests}

The authors declare that they have no competing interests.

\section{References}

1. Poddighe D: Mycoplasma pneumoniae-related hepatitis in children. Microb Pathog 139: 103863, 2020.

2. Waites KB, Xiao L, Liu Y, Balish MF and Atkinson TP: Mycoplasma pneumoniae from the respiratory tract and beyond. Clin Microbiol Rev 30: 747-809, 2017. 
3. Sánchez-Vargas FM and Gómez-Duarte OG Mycoplasma pneumoniae-an emerging extra-pulmonary pathogen. Clin Microbiol Infect 14: 105-117, 2008.

4. Katz B and Waites K: Emerging intracellular bacterial infections. Clin Lab Med 24: 627-649, 2004.

5. Rottem S: Interaction of mycoplasmas with host cells. Physiol Rev 83: 417-432, 2003.

6. Zlatian O, Balasoiu AT, Balasoiu M, Cristea O, Docea AO, Mitrut R, Spandidos DA, Tsatsakis AM, Bancescu G and Calina D: Antimicrobial resistance in bacterial pathogens among hospitalised patients with severe invasive infections. Exp Ther Med 16: 4499-4510, 2018

7. Ungureanu A, Zlatian O, Mitroi G, Drocas A, Tîrcă T, Călina D, Dehelean C, Docea AO, Izotov BN, Rakitskii VN, et al: Staphylococcus aureus colonisation in patients from a primary regional hospital. Mol Med Rep 16: 8771-8780, 2017.

8. Wang Z, Yang L, Ye J, Wang Y and Liu Y: Monocyte subsets study in children with Mycoplasma pneumoniae pneumonia. Immunol Res 67: 373-381, 2019

9. Jacobs E, Ehrhardt I and Dumke R: New insights in the outbreak pattern of Mycoplasma pneumoniae. Int J Med Microbiol 305: 705-708, 2015.

10. Meyer Sauteur PM, van Rossum AM and Vink C: Mycoplasma pneumoniae in children: Carriage, pathogenesis, and antibiotic resistance. Curr Opin Infect Dis 27: 220-227, 2014.

11. Wood PR, Hill VL, Burks ML, Peters JI, Singh H, Kannan TR, Vale S, Cagle MP, Principe MF, Baseman JB and Brooks EG: Mycoplasma pneumoniae in children with acute and refractory asthma. Ann Allergy Asthma Immunol 110: 328-334 e1, 2013.

12. Narita M: Classification of extrapulmonary manifestations due to Mycoplasma pneumoniae infection on the basis of possible pathogenesis. Front Microbiol 7: 23, 2016.

13. Canavan TN, Mathes EF, Frieden I and Shinkai K Mycoplasma pneumoniae-induced rash and mucositis as a syndrome distinct from Stevens-Johnson syndrome and erythema multiforme: A systematic review. J Am Acad Dermatol 72: 239-245, 2015.

14. Kuźma-Mroczkowska E, Pańczyk-Tomaszewska M, Szmigielska A, Szymanik-Grzelak H and Roszkowska-Blaim M: Mycoplasma pneumoniae as a trigger for Henoch-Schonlein purpura in children. Cent Eur J Immunol 40: 489-492, 2015.

15. Vijay A,Stendahl JC and Rosenfeld LE: Mycoplasma pneumoniae pericarditis. Am J Cardiol 123: 1383-1384, 2019

16. Lan Y, Li S, Yang D, Zhou J, Wang Y, Wang J, Xu Y and Chen Z: Clinical characteristics of Kawasaki disease complicated with Mycoplasma pneumoniae pneumonia: A retrospective study. Medicine (Baltimore) 99: e19987, 2020

17. Wandro C, Dolatshahi L and Blackall D: Severe warm autoimmune hemolytic anemia in a 7-month-old infant associated with a Mycoplasma pneumoniae infection. J Pediatr Hematol Oncol 40 : e439-e441, 2018

18. Gouveia C, Evangelista V, Almeida R and Baptista AM: Immune thrombocytopenia associated with Mycoplasma pneumoniae infection. Eur J Case Rep Intern Med 5: 000817, 2018.

19. Romero-Gómez M, Otero MA, Sánchez-Muñoz D Ramírez-Arcos M, Larraona JL, Suárez García E and Vargas-Romero J: Acute hepatitis due to Mycoplasma pneumoniae infection without lung involvement in adult patients. J Hepatol 44 827-828, 2006.

20. Valdés Lacasa T, Duarte Borges MA, García Marín A and Gómez Cuervo C: Acute pancreatitis caused by Mycoplasma pneumoniae: An unusual etiology. Clin J Gastroenterol 10: 279-282, 2017.

21. Meyer Sauteur PM, Huizinga R, Tio-Gillen AP, Drenthen J, Unger WWJ, Jacobs E, van Rossum AMC and Jacobs BC: Intrathecal antibody responses to GalC in Guillain-Barre syndrome triggered by Mycoplasma pneumoniae. J Neuroimmunol 314: 13-16, 2018

22. Coriolani G, Ferranti S, Squarci G and Grosso S: A case of Bickerstaff encephalitis associated with Mycoplasma pneumoniae infection. Neurol Sci 41: 1605-1606, 2020.

23. Siomou E, Kollios KD, Papadimitriou P, Kostoula A and Papadopoulou Z: Acute nephritis and respiratory tract infection caused by Mycoplasma pneumoniae: Case report and review of the literature. Pediatr Infect Dis J 22: 1103-1106, 2003.

24. Poddighe D: Mycoplasma pneumoniae-related extra-pulmonary diseases and antimicrobial therapy. J Microbiol Immunol Infect 53: 188-189, 2020.
25. Yang TI, Chang TH, Lu CY, Chen JM, Lee PI, Huang LM and Chang LY: Mycoplasma pneumoniae in pediatric patients: Do macrolide-resistance and/or delayed treatment matter? J Microbiol Immunol Infect 52: 329-335, 2019.

26. Poddighe D, Comi EV, Brambilla I, Licari A, Bruni P and Marseglia GL: Increased total serum immunoglobulin E in children developing Mycoplasma pneumoniae-related extra-pulmonary diseases. Iran J Allergy Asthma Immunol 17: 490-496, 2018

27. Poddighe D and Marseglia GL: Is there any relationship between extra-pulmonary manifestations of Mycoplasma pneumoniae infection and atopy/respiratory allergy in children? Pediatr Rep 8: 6395, 2016

28. Flateau C, Asfalou I, Deman AL, Ficko C, Andriamanantena D, Fontan E, Viant E, Bonnevie L and Rapp C: Aortic thrombus and multiple embolisms during a Mycoplasma pneumoniae infection. Infection 41: 867-873, 2013.

29. Dowd AB, Grace R and Rees WD: Cerebral infarction associated with Mycoplasma pneumoniae infection. Lancet 2: 567, 1987.

30. Choi YH, Jeong HJ, Lee B, An HY, Lee EJ and Park JD: Extensive and progressive cerebral infarction after Mycoplasma pneumoniae infection. Korean J Crit Care Med 32: 211-217, 2017.

31. Kim GH, Seo WH, Je BK and Eun SH: Mycoplasma pneumoniae associated stroke in a 3 -year-old girl. Korean J Pediatr 56 411-415, 2013.

32. Liu J, He R, Wu R, Wang B, Xu H, Zhang Y, Li H and Zhao S: Mycoplasma pneumoniae pneumonia associated thrombosis at Beijing Children's hospital. BMC Infect Dis 20: 51, 2020.

33. Ryu JS, Kim HJ, Sung IY and Ko TS: Posterior cerebral artery occlusion after Mycoplasma pneumoniae infection associated with genetic defect of MTHFR C677T. J Child Neurol 24: 891-894, 2009

34. Sarathchandran P, Al Madani A, Alboudi AM and Inshasi J: Mycoplasma pneumoniae infection presenting as stroke and meningoencephalitis with aortic and subclavian aneurysms without pulmonary involvement. BMJ Case Rep 2018: bcr2017221831, 2018.

35. Kang B, Kim DH, Hong YJ, Son BK, Lim MK, Choe YH and Kwon YS: Complete occlusion of the right middle cerebral artery associated with Mycoplasma pneumoniae pneumonia. Korean J Pediatr 59: 149-152, 2016.

36. Sotgiu S, Pugliatti M, Rosati G, Deiana GA and Sechi GP Neurological disorders associated with Mycoplasma pneumoniae infection. Eur J Neurol 10: 165-168, 2003

37. Van Dyke DC, Eldadah MK, Bale JF Jr, Kramer M, Alexander R, Smith WL and Olivero W: Mycoplasma pneumoniae-induced cerebral venous thrombosis treated with urokinase. Clin Pediatr (Phila) 31: 501-504, 1992.

38. Visudhiphan P, Chiemchanya S and Sirinavin S: Internal carotid artery occlusion associated with Mycoplasma pneumoniae infection. Pediatr Neurol 8: 237-239, 1992.

39. Antachopoulos C,Liakopoulou T, Palamidou F, Papathanassiou D ănd Youroukos S: Posterior cerebral artery occlusion associated with Mycoplasma pneumoniae infection. J Child Neurol 17: 55-57, 2002

40. Jin X, Zou Y, Zhai J, Liu J and Huang B: Refractory Mycoplasma pneumoniae pneumonia with concomitant acute cerebral infarction in a child: A case report and literature review. Medicine (Baltimore) 97: e0103, 2018.

41. Senda J, Ito M, Atsuta N, Watanabe H, Hattori N, Kawai H and Sobue G: Paradoxical brain embolism induced by Mycoplasma pneumoniae infection with deep venous thrombus. Intern Med 49: 2003-2005, 2010.

42. Garcia AV, Fingeret $A L$, Thirumoorthi AS, Kadenhe-Chiweshe A and Kandel JJ: Severe Mycoplasma pneumoniae infection requiring extracorporeal membrane oxygenation with concomitant ischemic stroke in a child. Pediatr Pulmonol 48 98-101, 2013

43. Garcia Tirado A, Jimenez-Rolando B, Noval S and Martinez Bermejo A: Cortical Blindness in a Child Secondary to Mycoplasma pneumoniae Infection. J Stroke Cerebrovasc Dis 26: e12-e13, 2017.

44. Fu M, Wong KS, Lam WW and Wong GW: Middle cerebral artery occlusion after recent Mycoplasma pneumoniae infection. J Neurol Sci 157: 113-115, 1998.

45. Socan M, Ravnik I, Bencina D, Dove P, Zakotnik B and Jazbec J: Neurological symptoms in patients whose cerebrospinal fluid is culture- and/or polymerase chain reaction-positive for Mycoplasma pneumoniae. Clin Infect Dis 32: E31-E35, 2001. 
46. Nagashima M, Higaki T, Satoh $\mathrm{H}$ and Nakano T: Cardiac thrombus associated with Mycoplasma pneumoniae infection. Interact Cardiovasc Thorac Surg 11: 849-851, 2010.

47. Oeser C, Andreas M, Rath C, Habertheuer A and Kocher A: Left ventricular thrombus in a patient with cutaneous T-cell lymphoma, hypereosinophilia and Mycoplasma pneumoniae infection-a challenging diagnosis: A case report. J Cardiothorac Surg 10: 21, 2015.

48. Pachet A, Dumestre-Perard C, Moine M, Marlu R, Rubio A and Bost-Bru C: Splenic infarction associated with transient anti-prothrombin antibodies is a rare manifestation of acute Mycoplasma pneumoniae infection. Arch Pediatr 26: 483-486, 2019.

49. Li Y, Pattan V, Syed B, Islam M and Yousif A: Splenic infarction caused by a rare coinfection of Epstein-Barr virus, cytomegalovirus, and Mycoplasma pneumoniae. Pediatr Emerg Care 30: 636-637, 2014

50. Park SJ, Lee YM, Lee CH, Cho JH and Lee JH: A case of splenic infarction possibly attributable to Mycoplasma pneumoniae infection without accompanying pneumonia. J Infect Chemother 18: 945-947, 2012.

51. Witmer CM, Steenhoff AP, Shah SS and Raffini LJ: Mycoplasma pneumoniae, splenic infarct, and transient antiphospholipid antibodies: A new association? Pediatrics 119: e292-e295, 2007

52. Liu J, Zhao F, Lu J, Xu H, Liu H, Tang X, Yang H, Zhang J and Zhao S: High Mycoplasma pneumoniae loads and persistent long-term Mycoplasma pneumoniae DNA in lower airway associated with severity of pediatric Mycoplasma pneumoniae pneumonia. BMC Infect Dis 19: 1045, 2019.

53. Chen Y, Huang P, Chen Q, Lin Z and Tian W: Two separated thrombi in deep veins associated with pulmonary embolism after Mycoplasma pneumoniae infection: A case in adolescent female. Transl Pediatr 2: 198-201, 2013.

54. Graw-Panzer KD, Verma S, Rao S, Miller ST and Lee H: Venous thrombosis and pulmonary embolism in a child with pneumonia due to Mycoplasma pneumoniae. J Natl Med Assoc 101: 956-958, 2009.

55. Joo CU, Kim JS and Han YM: Mycoplasma pneumoniae induced popliteal artery thrombosis treated with urokinase. Postgrad Med J 77: 723-724, 2001.

56. Creagh MD, Roberts IF, Clark DJ and Preston FE: Familial antithrombin III deficiency and Mycoplasma pneumoniae pneumonia. J Clin Pathol 44: 870-871, 1991.

57. Kalicki B, Sadecka M, Wawrzyniak A, Kozinski P, Dziekiewicz $M$ and Jung A: Absence of inferior vena cava in 14-year old boy associated with deep venous thrombosis and positive Mycoplasma pneumoniae serum antibodies-a case report. BMC Pediatr 15: 40, 2015.

58. Caeiro Alves F, Aguiar R, Pessegueiro P and Pires C: Thrombotic microangiopathy associated with Mycoplasma pneumoniae infection. BMJ Case Rep 2018: bcr2017222582, 2018.

59. Godron A, Pereyre S, Monet C, Llanas B and Harambat J: Hemolytic uremic syndrome complicating Mycoplasma pneumoniae infection. Pediatr Nephrol 28 2057-2060, 2013.

60. Bar Meir E, Amital H, Levy Y, Kneller A, Bar-Dayan Y and Shoenfeld Y: Mycoplasma-pneumoniae-induced thrombotic thrombocytopenic purpura. Acta Haematol 103: 112-115, 2000.

61. Cameron D, Welsby $\mathrm{P}$ and Turner M: Thrombotic thrombocytopenic purpura due to Mycoplasma pneumoniae. Postgrad Med J 68: 393-394, 1992.

62. Byrnes JR and Wolberg AS: Red blood cells in thrombosis Blood 130: 1795-1799, 2017.

63. Li T, Yu H, Hou W, Li Z, Han C and Wang L: Evaluation of variation in coagulation among children with Mycoplasma pneumoniae pneumonia: A case-control study. J Int Med Res 45: 2110-2118, 2017

64. Connors JM: Thrombophilia testing and venous thrombosis. N Engl J Med 377: 1177-1187, 2017.

65. Narita M: Pathogenesis of extrapulmonary manifestations of Mycoplasma pneumoniae infection with special reference to pneumonia. J Infect Chemother 16: 162-169, 2010.

66. Higuchi ML, Sambiase N, Palomino S, Gutierrez P, Demarchi LM, Aiello VD and Ramires JA: Detection of Mycoplasma pneumoniae and Chlamydia pneumoniae in ruptured atherosclerotic plaques. Braz J Med Biol Res 33: 1023-1026, 2000

67. Higuchi Mde L, Reis MM, Sambiase NV, Palomino SA, Castelli JB, Gutierrez PS, Aiello VD and Ramires JA: Coinfection with Mycoplasma pneumoniae and Chlamydia pneumoniae in ruptured plaques associated with acute myocardial infarction. Arq Bras Cardiol 81: 1-22, 2003
68. Cho A, Ragi SD, Oh JK, Lima de Carvalho JR Jr, Ryu J, Yang BY and Tsang SH: Sequential multiple retinal vein occlusions and transient ischemic attack in MTHFR polymorphism and protein S deficiency. Mol Genet Genomic Med 8: e1273, 2020.

69. Gatt A and Makris M: Hyperhomocysteinemia and venous thrombosis. Semin Hematol 44: 70-76, 2007.

70. Cheng Z, Jiang X, Pansuria M, Fang P, Mai J, Mallilankaraman K, Gandhirajan RK, Eguchi S, Scalia R, Madesh M, et al: Hyperhomocysteinemia and hyperglycemia induce and potentiate endothelial dysfunction via $\mu$-calpain activation. Diabetes 64 : 947-959, 2015.

71. Ospina-Romero M, Cannegieter SC, den Heijer M, Doggen CJM, Rosendaal FR and Lijfering WM: Hyperhomocysteinemia and risk of first venous thrombosis: The influence of (Unmeasured) confounding factors. Am J Epidemiol 187: 1392-1400, 2018.

72. Muszbek L,Bereczky Z,Kovács B and Komáromi I: Antithrombin deficiency and its laboratory diagnosis. Clin Chem Lab Med 48 (Suppl 1): S67-S78, 2010

73. Pabinger I and Thaler J: How I treat patients with hereditary antithrombin deficiency. Blood 134: 2346-2353, 2019.

74. Patnaik MM and Moll S: Inherited antithrombin deficiency: A review. Haemophilia 14: 1229-1239, 2008.

75. Wang D, Lv W, Zhang S and Zhang J: Advances in the research on anticardiolipin antibody. J Immunol Res 2019: 8380214, 2019.

76. Habe K, Wada H, Matsumoto T, Ohishi K, Ikejiri M, Matsubara K, Morioka T, Kamimoto Y, Ikeda T, Katayama N, et al: Presence of antiphospholipid antibody is a risk factor in thrombotic events in patients with antiphospholipid syndrome or relevant diseases. Int J Hematol 97: 345-350, 2013.

77. Sacharidou A, Chambliss KL, Ulrich V, Salmon JE, Shen YM, Herz J, Hui DY, Terada LS, Shaul PW and Mineo C: Antiphospholipid antibodies induce thrombosis by PP2A activation via apoER2-Dab2-SHC1 complex formation in endothelium. Blood 131: 2097-2110, 2018.

78. Ortel TL, Meleth S, Catellier D, Crowther M, Erkan D, Fortin PR, Garcia D, Haywood N, Kosinski AS, Levine SR, et al: Recurrent thrombosis in patients with antiphospholipid antibodies and an initial venous or arterial thromboembolic event: A systematic review and meta-analysis. J Thromb Haemost 18: 2274-2286, 2020.

79. Zohoury N, Bertolaccini ML, Rodriguez-Garcia JL, Shums Z, Ateka-Barrutia O, Sorice M, Norman GL and Khamashta M: Closing the serological gap in the antiphospholipid syndrome: the value of 'non-criteria' antiphospholipid antibodies. J Rheumatol 44: 1597-1602, 2017.

80. Sciascia S, Sanna G, Murru V, Roccatello D, Khamashta MA and Bertolaccini ML: Anti-prothrombin (aPT) and anti-phosphatidylserine/prothrombin (aPS/PT) antibodies and the risk of thrombosis in the antiphospholipid syndrome. A systematic review. Thromb Haemost 111: 354-364, 2014.

81. Ho WK and Rigano J: Prevalence of autoantibodies directed against prothrombin in unprovoked venous thromboembolism. J Thromb Thrombolysis 49: 446-450, 2020.

82. Berentsen S: Complement activation and inhibition in autoimmune hemolytic anemia: Focus on cold agglutinin disease. Semin Hematol 55: 141-149, 2018.

83. Habib A, Kunzelmann C, Shamseddeen W, Zobairi F, Freyssinet JM and Taher A: Elevated levels of circulating procoagulant microparticles in patients with beta-thalassemia intermedia. Haematologica 93: 941-942, 2008.

84. Zhou Z, Behymer M and Guchhait P: Role of extracellular hemoglobin in thrombosis and vascular occlusion in patients with sickle cell anemia. Anemia 2011: 918916, 2011.

85. Rother RP, Bell L, Hillmen P and Gladwin MT: The clinical sequelae of intravascular hemolysis and extracellular plasma hemoglobin: A novel mechanism of human disease. JAMA 293: 1653-1662, 2005.

86. Skuza AA, Polak M and Undas A: Elevated lipoprotein(a) as a new risk factor of cerebral venous sinus thrombosis: Association with fibrin clot properties. J Thromb Thrombolysis 47: 8-15, 2019.

87. Anglés-Cano E, de la Peña Díaz A and Loyau S: Inhibition of fibrinolysis by lipoprotein(a). Ann N Y Acad Sci 936: 261-275, 2001.

88. Feric NT, Boffa MB, Johnston SM and Koschinsky ML: Apolipoprotein(a) inhibits the conversion of Glu-plasminogen to Lys-plasminogen: A novel mechanism for lipoprotein(a)-mediated inhibition of plasminogen activation. J Thromb Haemost 6 : 2113-2120, 2008.

89. Rouy D, Grailhe P, Nigon F, Chapman J and Anglés-Cano E: Lipoprotein(a) impairs generation of plasmin by fibrin-bound tissue-type plasminogen activator. In vitro studies in a plasma milieu. Arterioscler Thromb 11: 629-638, 1991. 
90. Chew RR, Lim AH and Toh D: Congenital absence of inferior vena cava: An under recognised cause of unprovoked venous thromboembolism. QJM 111: 117-118, 2018.

91. Gökçe Ş, Keskin G, Yaşar ŞK, Arslan AT, Cerit Z, Koska Öİ and Aydoğdu S: A case of May-Thurner Syndrome: An old anomaly but, a new suggestion: A case report. Malawi Med J 31: 230-232, 2019.

92. Ho AMH, Chung AD and Mizubuti GB: A hairdresser's painful swollen left leg: Artery compresses vein in May-Thurner syndrome. Lance 394: e33, 2019.

93. Yang S, You R, Wu W, Wei Z, Hong M and Peng Z: Dural arteriovenous fistula complicated with cerebral venous sinus thrombosis. World Neurosurg 134: 348-352, 2020.

94. Carqueja IM, Sousa J and Mansilha A: Vascular malformations: Classification, diagnosis and treatment. Int Angiol 37: 127-142, 2018.

95. Jensen CT, Chahin A, Amin VD, Khalaf AM, Elsayes KM, Wagner-Bartak N, Zhao B, Zhou S and Bedi DG: Qualitative slow blood flow in lower extremity deep veins on doppler sonography: Quantitative assessment and preliminary evaluation of correlation with subsequent deep venous thrombosis development in a tertiary care oncology center. J Ultrasound Med 36: 1867-1874, 2017.

96. Roggério A, Sambiase NV, Palomino SA, de Castro MA, da Silva ES, Stolf NG and de Lourdes Higuchi M: Correlation of bacterial coinfection versus matrix metalloproteinase 9 and tissue inhibitor of metalloproteinase 1 expression in aortic aneurysm and atherosclerosis. Ann Vasc Surg 27: 964-971, 2013.

97. Hellwig K, Hoffmann L, Rother U, Meyer A, Lang W and Schmid A: Eligibility of endovascular repair for popliteal artery aneurysms according the instructions for use. Ann Vasc Surg 67: 370-375, 2020 .

98. Wehbe E, Abou Antoun S and Peery WH: An unusual complication of sickle cell trait: Intraureter thrombus. Int Uro Nephrol 42: 517-518, 2010

99. Ali JM, Besser M, Goddard M, Abu-Omar Y, Catarino P, Bhagra $S$ and Berman M: Catastrophic sickling crisis in patient undergoing cardiac transplantation with sickle cell trait. Am J Transplant 19: 2378-2382, 2019.

100. Kumar R, Kapoor R, Singh J, Das S, Sharma A, Yanamandra U and Nair V: Splenic infarct on exposure to extreme high altitude in individuals with sickle trait: A single-center experience. High Alt Med Biol 20: 215-220, 2019.

101. Tripette J, Hardy-Dessources MD, Romana M, Hue O, Diaw M, Samb A, Diop S and Connes P: Exercise-related complications in sickle cell trait. Clin Hemorheol Microcirc 55: 29-37, 2013.

102. Eichner ER: Sickle cell considerations in athletes. Clin Sports Med 30: 537-549, 2011
103. Vincent L, Féasson L, Oyono-Enguéllé S, Banimbek V, Denis C, Guarneri C, Aufradet E, Monchanin G, Martin C, Gozal D, et al: Remodeling of skeletal muscle microvasculature in sickle cell trait and alpha-thalassemia. Am J Physiol Heart Circ Physiol 298: H375-H384, 2010.

104. Faës C, Martin C, Chirico EN, Féasson L, Oyonno-Enguelle S, Dubouchaud H, Francina A, Thiriet P, Pialoux V and Messonnier L: Effect of $\alpha$-thalassaemia on exercise-induced oxidative stress in sickle cell trait. Acta Physiol (Oxf) 205: $541-550,2012$.

105. South K and Lane DA: ADAMTS-13 and von Willebrand factor: A dynamic duo. J Thromb Haemost 16: 6-18, 2018.

106. Ono T, Mimuro J, Madoiwa S, Soejima K, Kashiwakura Y, Ishiwata A, Takano K, Ohmori T and Sakata Y: Severe secondary deficiency of von Willebrand factor-cleaving protease (ADAMTS13) in patients with sepsis-induced disseminated intravascular coagulation: Its correlation with development of renal failure. Blood 107: 528-534, 2006.

107. Levi M, Scully M and Singer M: The role of ADAMTS-13 in the coagulopathy of sepsis. J Thromb Haemost 16: 646-651, 2018.

108. Chen $\mathrm{J}$ and Chung DW: Inflammation, von Willebrand factor, and ADAMTS13. Blood 132: 141-147, 2018.

109. Bernardo A, Ball C, Nolasco L, Moake JF and Dong JF: Effects of inflammatory cytokines on the release and cleavage of the endothelial cell-derived ultralarge von Willebrand factor multimers under flow. Blood 104: 100-106, 2004.

110. Wypasek E and Undas A: Protein $C$ and protein $S$ deficiency-practical diagnostic issues. Adv Clin Exp Med 22: 459-467, 2013

111. Dinarvand P and Moser KA: Protein C deficiency. Arch Pathol Lab Med 143: 1281-1285, 2019.

112. Padda IS, Patel P and D Citla Sridhar D: Protein S and C. In: StatPearls. Treasure Island (FL), StatPearls Publishing Copyright (c) 2020, StatPearls Publishing LLC, 2020.

113. Girolami A, Cosi E, Ferrari S and Girolami B: Heparin, coumarin, protein $\mathrm{C}$, antithrombin, fibrinolysis and other clotting related resistances: Old and new concepts in blood coagulation. J Thromb Thrombolysis 45: 135-141, 2018.

114. Mirijello A, La Marca A, D'Errico MM, Curci S, Vendemiale G, Grandone E and De Cosmo S: Venous thromboembolism during Mycoplasma pneumoniae infection: Case report and review of the literature. Eur Rev Med Pharmacol Sci 24: 10061-10068, 2020.

cc) (i) $\odot$ This work is licensed under a Creative Commons c) ${ }_{\mathrm{EY}}$ NC ND Attribution-NonCommercial-NoDerivatives 4.0 International (CC BY-NC-ND 4.0) License. 